\title{
Relating gastric scintigraphy and symptoms to motility capsule transit and pressure findings in suspected gastroparesis
}

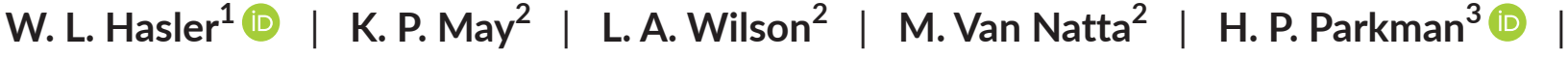

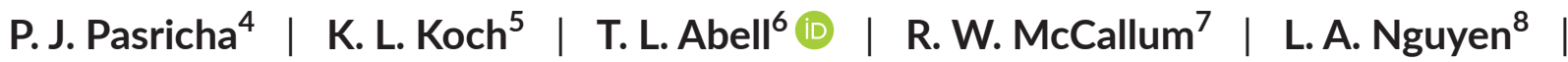 \\ W. J.Snape ${ }^{9}$ | I. Sarosiek ${ }^{7}$ | J. O. Clarke ${ }^{8}$ | G. Farrugia ${ }^{10}$ | J.Calles-Escandon ${ }^{11}$ | \\ M. Grover $^{10}$ | J. Tonascia ${ }^{2}$ | L. A. Lee ${ }^{12}$ | L. Miriel ${ }^{2}$ | F. A. Hamilton ${ }^{13}$ | the NIDDK \\ Gastroparesis Clinical Research Consortium (GpCRC)
}

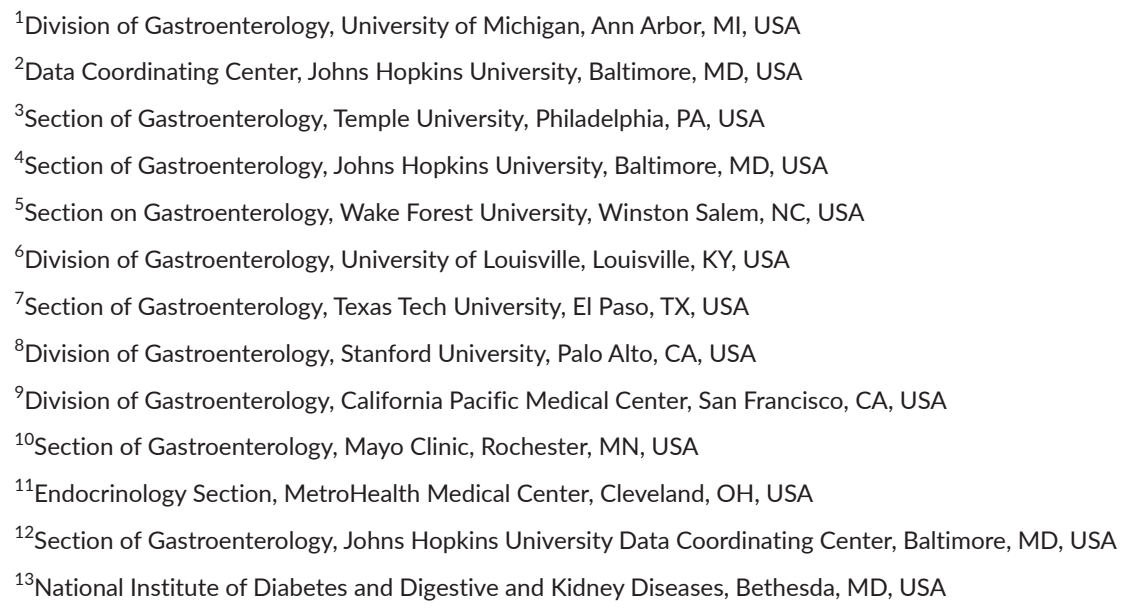

\section{Correspondence}

William L. Hasler, MD, University of Michigan Health System, Ann Arbor, MI, USA.

Email: whasler@umich.edu

Funding information

This project received support from the National Institute of Diabetes and Digestive and Kidney Diseases (NIDDK) (grants U01DK073983, U01DK073975, U01DK073985, U01DK074007, U01DK073974, U01DK074008) as part of its funding of the Gastroparesis Clinical Research Consortium.

\begin{abstract}
Background: Wireless motility capsule (WMC) findings are incompletely defined in suspected gastroparesis. We aimed to characterize regional WMC transit and contractility in relation to scintigraphy, etiology, and symptoms in patients undergoing gastric emptying testing.

Methods: A total of 209 patients with gastroparesis symptoms at NIDDK Gastroparesis Consortium centers underwent gastric scintigraphy and WMCs on separate days to measure regional transit and contractility. Validated questionnaires quantified symptoms.

Key Results: Solid scintigraphy and liquid scintigraphy were delayed in $68.8 \%$ and $34.8 \%$ of patients; WMC gastric emptying times (GET) were delayed in $40.3 \%$ and showed $52.8 \%$ agreement with scintigraphy; $15.5 \%$ and $33.5 \%$ had delayed small bowel (SBTT) and colon transit (CTT) times. Transit was delayed in $\geq 2$ regions in $23.3 \%$.
\end{abstract}


Rapid transit was rarely observed. Diabetics had slower GET but more rapid SBTT versus idiopathics $(P \leq .02)$. GET delays related to greater scintigraphic retention, slower SBTT, and fewer gastric contractions $(P \leq .04)$. Overall gastroparesis symptoms and nausea/vomiting, early satiety/fullness, bloating/distention, and upper abdominal pain subscores showed no relation to WMC transit. Upper and lower abdominal pain scores $(P \leq .03)$ were greater with increased colon contractions. Constipation correlated with slower CTT and higher colon contractions $(P=.03)$. Diarrhea scores were higher with delayed SBTT and CTT ( $P \leq .04)$.

Conclusions \& Inferences: Wireless motility capsules define gastric emptying delays similar but not identical to scintigraphy that are more severe in diabetics and relate to reduced gastric contractility. Extragastric transit delays occur in $>40 \%$ with suspected gastroparesis. Gastroparesis symptoms show little association with WMC profiles, although lower symptoms relate to small bowel or colon abnormalities.

\section{KEYWORDS}

contractility, gastric emptying, scintigraphy, small bowel and colon transit

\section{1 | INTRODUCTION}

Gastroparesis presents with nausea, vomiting, early satiety, fullness, bloating, and pain with objective evidence of delayed gastric emptying. ${ }^{1}$ The diagnosis of gastroparesis may be made by scintigraphy or by gastric emptying breath testing. ${ }^{2-4} A$ third method, wireless motility capsule (WMC) testing, is approved to quantify gastric emptying in suspected gastroparesis by detecting $\mathrm{pH}$ increases as the capsule passes from the stomach to duodenum. ${ }^{5} \mathrm{WMC}$ gastric emptying times correlated well with scintigraphic emptying in a smaller prior report. ${ }^{5}$

Although presumed to originate in the stomach, gastroparesis symptoms are non-specific and may be reported with other lower functional gastrointestinal disorders. ${ }^{6,7}$ Gastroparesis patients also describe bowel disturbances suggesting involvement of multiple gut regions. ${ }^{8,9}$ WMC methods offer expanded capabilities over scintigraphy, providing small bowel and colon transit measurements in generalized motility disorders. ${ }^{10-12}$ Retrospective WMC series have defined extragastric transit delays in some patients with presumed gastroparesis. ${ }^{13,14}$ The WMC pressure sensor estimates contractility in different gut regions. ${ }^{15}$ Reduced gastric and colon contractions have been defined in small gastroparesis cohorts. ${ }^{16,17}$ However, abnormalities of transit and contractility in different gut regions have not been contrasted in patients with diabetic versus idiopathic gastroparesis.

The importance of gastric and extragastric transit and contractility abnormalities in causing gastroparesis symptoms is unproved. Symptom severities measured using standardized questionnaires from a large registry of patients with such symptoms were not different in those with delayed versus normal gastric emptying measured by scintigraphy. ${ }^{18}$ In that report, a novel patient subgroup with similar symptoms as gastroparesis but with normal emptying, termed chronic unexplained nausea and vomiting (CUNV), was defined. In one retrospective WMC assessment of patients with generalized

\section{Key Points}

- Wireless motility capsule (WMC) findings in suspected gastroparesis and relations to symptoms have been poorly defined.

- Evaluation of patients with gastroparesis symptoms revealed gastric emptying delays with WMCs that were similar to scintigraphy, were related to reduced contractility, and were often associated with extragastric or generalized transit delays; symptoms correlated poorly with WMC profiles.

- These findings provide insight into motor abnormalities in gastroparesis pathogenesis and form a basis for future investigations studying the impact of WMC testing on clinical care.

dysmotility symptoms, upper and lower gut symptoms did not predict transit abnormalities. ${ }^{12}$ However, duodenal contractility on WMC tests negatively correlated with overall symptom severity in another small gastroparesis cohort. ${ }^{19}$ Drawbacks of older WMC studies in gastroparesis include their retrospective nature, small sample sizes, non-standardized gastric scintigraphy methods, and lack of symptom characterizations using validated surveys.

This investigation related prospective WMC data from a large, multicenter cohort from the NIDDK Gastroparesis Consortium to standardized gastric scintigraphy findings and gastrointestinal symptoms quantified by validated questionnaires. Specific aims were to: (i) characterize WMC gastric and extragastric transit and contractility in suspected gastroparesis, including comparisons in diabetic versus idiopathic patients, (ii) associate gastric emptying delays measured by 
WMC and scintigraphy with other transit and contractility measures in suspected gastroparesis and provide insight into CUNV pathogenesis, and (iii) relate symptom severity to WMC transit and contractility to ascribe potential pathogenic roles for motor dysfunction to symptom genesis. These analyses defined the breadth and pathophysiologic importance of motor abnormalities in suspected gastroparesis to form a foundation for future studies investigating the impact of WMC testing on decision making and outcomes. Some data within this study were presented at Digestive Disease Week in 2015 and 2016. ${ }^{20,21}$

\section{MATERIALS AND METHODS}

\section{1 | Patient populations}

Two hundred and nine patients with suspected gastroparesis underwent WMC testing after enrollment in the Gastroparesis Registry 2 (GpR2) at the 8 centers of the Gastroparesis Clinical Research Consortium (GpCRC) from March 2013 to March 2016 (ClinicalTrials. gov NCT01696747). Patients reported gastroparesis symptoms $\geq 12$ weeks of duration and showed no organic disease on endoscopy within 12 months before enrollment. WMC testing was not performed in patients with known bezoars (poorly organized food residue was permitted), dysphagia, prior gut surgery, GI strictures, prior inflammatory bowel disease or diverticulitis, frequent nonsteroidal anti-inflammatory drug use, and cardiac medical devices (gastric stimulators, insulin pumps, glucose monitors were permitted). Attribution of gastroparesis to diabetic versus idiopathic versus other etiologies was made by site investigators based on patient self-report and medical record review. Within 6 months before GpR2 enrollment, patients underwent scintigraphy to quantify solid and liquid gastric emptying. The solid-phase meal was comprised of ${ }^{99 \mathrm{~m}}$ Tc-sulfur colloid-labeled egg substitute meals which included $120 \mathrm{~g}$ EggBeaters ${ }^{\circledR}, 2$ slices of bread, $30 \mathrm{~g}$ strawberry jam, and $120 \mathrm{~mL}$ water $(255 \mathrm{kcal}, 72 \%$ carbohydrate, $24 \%$ protein, $2 \%$ fat, $2 \%$ fiber). ${ }^{3}$ One hundred and forty-nine of the 209 patients underwent concurrent liquid gastric emptying scintigraphy with consumption of $120 \mathrm{~mL}{ }^{111}$ In-DTPA (diethylenetriaminepentaacetic acid)-labeled water along with the solid meal. ${ }^{22}$

Studies were approved by Institutional Review Boards at all Clinical Centers and the Data Coordinating Center. Patients provided written informed consent. All authors had access to study data and reviewed and approved the final manuscript.

\section{2 $\quad$ WMC testing}

Patients underwent WMC (SmartPill ${ }^{\circledR}$; Medtronic, Minneapolis, MN, USA) testing using accepted protocols. ${ }^{14,15,23}$ The WMC measures $26.8 \mathrm{~mm} \times 11.7 \mathrm{~mm}$ and transmits data to a receiver. WMC sensors measure intraluminal pH (every 5 seconds for the first 24 hours, every 10 seconds from 24 to 48 hours, and every 2.5 minutes after 48 hours; accurate to $\pm 0.5 \mathrm{pH}$ units), pressure from 0 to $350 \mathrm{~mm} \mathrm{Hg}$ (every 0.5 seconds for the first 24 hours, every second afterward; accurate to $\pm 5 \mathrm{~mm} \mathrm{Hg}<100 \mathrm{~mm} \mathrm{Hg}$ and $\pm 10 \%>100 \mathrm{~mm} \mathrm{Hg}$ ), and temperature from 25 to $49^{\circ} \mathrm{C}$ (every 20 seconds for the first 24 hours, every
40 seconds afterward; accurate to $\left.\pm 1^{\circ} \mathrm{C}\right) .{ }^{14,15,23}$ Before WMC testing, patients stopped proton pump inhibitors for 7 days, and histamine ${ }_{2}-$ receptor antagonists, prokinetics (metoclopramide, domperidone, erythromycin), opiates, anticholinergics, cannabinoids, over-thecounter laxatives, isotonic polyethylene glycol electrolyte preparations, and prescription laxatives (lubiprostone, linaclotide, misoprostol) for 3 days. On the evening before testing, insulin-requiring diabetics injected half of their usual long-acting insulin dose. Patients fasted overnight before testing. Urine pregnancy tests were performed for female patients of child-bearing potential on the day of WMC ingestion. Fingerstick glucose measurements were made in diabetic patients; studies were rescheduled if fasting glucose levels exceeded $270 \mathrm{mg} / \mathrm{dL}$. Each patient then ingested one SmartBar ${ }^{\circledR}$ (Medtronic) with similar caloric content as the radiolabelled egg substitute meal (255 kcal, 66\% carbohydrate, 17\% protein, 2\% fat, 3\% fiber) over 10 minutes with $\leq 50 \mathrm{~mL}$ water. After consuming the SmartBar ${ }^{\circledR}$, the WMC was swallowed with another $50 \mathrm{~mL}$ of water. Patients fasted for 6 hours after WMC ingestion and then resumed normal diets. They were instructed to keep the data receiver within 3 feet of their bodies at all times for the next 4-7 days until they returned the data receiver. Patients continued to abstain from proton pump inhibitors and medications that influence gut transit over this 4- to 7-day period.

Gastric emptying times (GET) were calculated from the time of WMC ingestion to when the capsule passed into the duodenum, as defined by abrupt $\geq 2 \mathrm{pH}$ unit increases from the lowest postprandial value to levels $\geq 4$ that persisted for at least 10 minutes. WMC ileocecal junction transit was detected when $\mathrm{pH}$ decreased $\geq 1.0 \mathrm{pH}$ unit for at least 10 minutes $\geq 30$ minutes after pyloric passage. WMC small bowel transit times (SBTT) were calculated from the end of the GET period to ileocecal junction passage. Anal WMC evacuation was detected by abrupt $0.025^{\circ} \mathrm{C}$ per second decreases in temperature. WMC colon transit times (CTT) were calculated from the end of the SBTT period to the time of anal capsule expulsion. WMC contractions $>10 \mathrm{mmHg}$ in amplitude were quantified in the hour before GET to measure gastric contractility while contractions in the hour after GET determined small bowel contractility as described previously. ${ }^{13}$ Motility indices (MI) in the hour before (gastric) and after GET (small bowel) were calculated from the logarithmic transformation of the areas under the contraction curves. Numbers of contractions $>25 \mathrm{~mm} \mathrm{Hg}$ in amplitude per hour and $\mathrm{MI}$ were calculated for the entire period of colon transit using accepted methods. ${ }^{24}$ Normal gastric emptying times (GET) $(\leq 5$ and $>1: 45$ hours), small bowel transit times (SBTT) ( $\leq 6$ and $>2: 15$ hours), and colon transit times $(C T T)(\leq 58: 45$ and $>4: 30$ hours) were defined in a recent report. ${ }^{23}$ Severely delayed GET ( $>12$ hours) was defined as previously. ${ }^{16}$ Numbers of contractions and motility indices (MI) for each region were calculated as measures of contractility. ${ }^{16,23}$ Numbers of gastric and small bowel contractions $<29 /$ hour and $<36 /$ hour and gastric and small bowel $\mathrm{Ml}<9.82$ and $<10.57$, respectively, have been defined as below the 5 th percentile for normal volunteers. ${ }^{16}$ Normal cutoffs for numbers of contractions and $\mathrm{MI}$ for the colon have not been defined. Patients also were stratified into those with high versus low contraction numbers and $\mathrm{MI}$ in each region such that roughly half were in each group to relate symptoms to contractility. 
(A) Normal transit

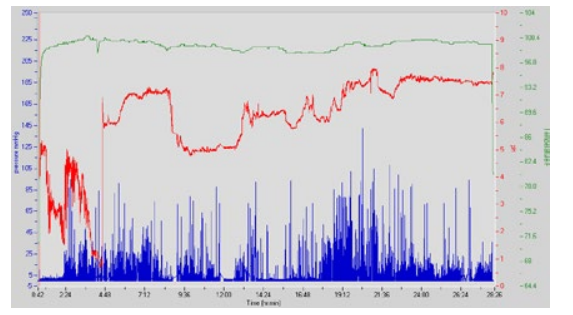

\begin{tabular}{|c|c|}
\hline Region & $\begin{array}{c}\text { Time } \\
\text { (h:min) }\end{array}$ \\
\hline GET & $3: 48$ \\
\hline SBTT & $4: 00$ \\
\hline CTT & $19: 39$ \\
\hline
\end{tabular}

(B) Mild GET delay

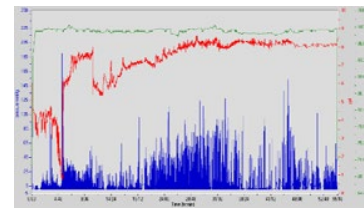

(D) CTT delay

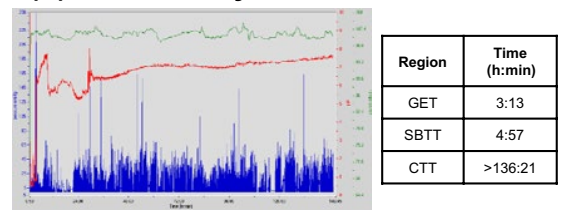

\begin{tabular}{|c|c|}
\hline Region & $\begin{array}{c}\text { Time } \\
\text { (h:min) }\end{array}$ \\
\hline GET & $5: 32$ \\
\hline SBTT & $5: 24$ \\
\hline CTT & $44: 03$ \\
\hline
\end{tabular}

(C) Severe GET delay

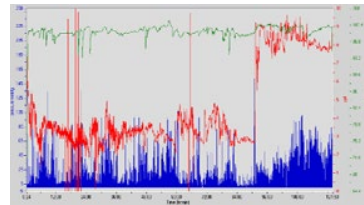

(E) Generalized delay

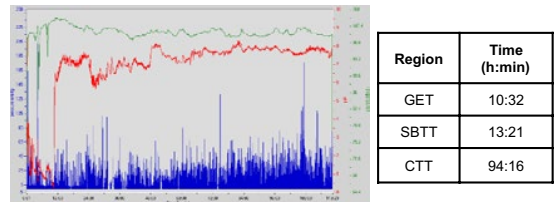

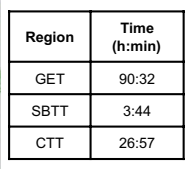

FIGURE 1 Representative WMC recordings from patients with (A) normal transit throughout, (B) mildly delayed GET, (C) severely delayed GET, (D) delayed CTT, and (E) generalized GET, SBTT, and CTT delays are shown (normal GET $\leq 5 \mathrm{~h}$, normal $\mathrm{SBTT} \leq 6 \mathrm{~h}$, normal $\mathrm{CTT} \leq 58: 45 \mathrm{~h}$ ). Transit times are calculated from $\mathrm{pH}$ transitions (red tracings) and temperature changes (green tracings). Pressure recordings are shown in blue

\section{3 | Symptom assessment}

Symptoms were quantified by modified Patient Assessment of Upper Gastrointestinal Disorders Symptoms (PAGI-SYM) questionnaires enumerating 22 symptoms from 0 (no symptoms) to 5 (most severe). ${ }^{25}$ Overall gastroparesis severity was determined by the Gastroparesis Cardinal Symptom Index (GCSI) score, which includes nine questions from the PAGI-SYM. ${ }^{26}$ PAGI-SYM subscale scores for upper GI symptoms were calculated for nausea/vomiting, postprandial fullness/early satiety, bloating/visible distention, and upper abdominal pain/discomfort. The nausea/vomiting subscale score was the mean of scores for nausea [feeling sick to your stomach as if you were going to vomit or throw up], retching [heaving as if to vomit, but nothing comes up], and vomiting. The postprandial fullness/early satiety subscale score was the mean of scores for stomach fullness, not able to finish a normalsized meal, feeling excessively full after meals, and loss of appetite. The bloating/visible distention subscale score was the mean of scores for bloating [feeling like you need to loosen your clothes] and stomach or belly visibly larger. The upper abdominal pain/discomfort subscale score referred to symptoms above the navel, while the lower abdominal pain/discomfort subscale score described symptoms below the navel. PAGI-SYM subscale scores for lower abdominal pain/discomfort and individual symptom scores for constipation and diarrhea quantified lower Gl symptoms.

\section{4 | Data comparisons}

Delayed scintigraphic solid gastric emptying (>10\% 4-hour retention and/or $>60 \%$ 2-hour retention) was compared in patients with normal versus delayed WMC GET to determine agreement between methods. Delayed SBTT and CTT were related to normal versus delayed
GET to correlate gastric emptying with extragastric transit. ${ }^{23} \mathrm{WMC}$ gastric, small bowel, and colon contraction numbers and $\mathrm{MI}$ were compared between normal versus delayed GET to relate contractility to gastric emptying. Scintigraphy and WMC measures were compared in diabetic versus idiopathic patients to contrast motor abnormalities between etiologies. Although their data were incorporated into analyses of the entire cohort, postfundoplication gastroparesis patients were not included in subgroup analyses related to etiology due to the small sample size $(\mathrm{N}=8)$. Data from patients with rapid scintigraphic gastric emptying (<38\% 1-hour retention), GET ( $N=10)$, SBTT $(N=8)$, and CTT $(\mathrm{N}=6)$ were not analyzed separately due to small samples and were pooled in with normal transit groups. To gain insight into CUNV pathogenesis, GET, SBTT, and CTT results were compared in patients with normal versus delayed solid scintigraphy. Gastric, small bowel, and colon contraction numbers and MI were contrasted with normal and delayed solid scintigraphy to ascertain whether CUNV presents with specific contractility profiles.

Overall GCSI scores, PAGI-SYM subscores, and individual PAGISYM lower GI symptoms were compared in those with delayed versus normal GET, SBTT, and CTT and with high versus low numbers of contractions and $\mathrm{MI}$ in the hour before and after GET and during the period of colon transit.

\section{5 | Statistical analyses}

Exploratory data analyses using means, medians, standard deviation, and interquartile ranges (IQR) were applied to WMC and scintigraphic measures and by comparing patients with diabetic versus idiopathic gastroparesis, normal versus delayed GET, and normal versus delayed scintigraphy. Differences between groups were compared using Wilcoxon rank-sum testing for continuous measures or Fisher's 
TAB LE 1 Prevalence of transit delays and contractility abnormalities in patients with suspected diabetic or idiopathic gastroparesis

\begin{tabular}{|c|c|c|c|c|}
\hline Measure & $\begin{array}{l}\text { All patients } \\
N(\%) \text { or Median (IQR) }\end{array}$ & $\begin{array}{l}\text { Diabetic patients } \\
\mathrm{N}(\%) \text { or Median (IQR) }\end{array}$ & $\begin{array}{l}\text { Idiopathic patients } \\
\mathrm{N}(\%) \text { or Median (IQR) }\end{array}$ & $\begin{array}{l}P \text { value diabetic } \\
\text { vs idiopathic } \\
\text { patients }\end{array}$ \\
\hline $\begin{array}{l}\text { Delayed scintigraphic } 4 \mathrm{~h} \text { solid } \\
\text { retention }>10 \%\end{array}$ & $132 / 194(68.8 \%)$ & $48 / 66(72.7 \%)$ & $84 / 126(66.7 \%)$ & .42 \\
\hline $\begin{array}{l}\text { Delayed scintigraphic } 1 \mathrm{~h} \text { liquid } \\
\text { retention }>50 \%\end{array}$ & $48 / 137(34.8 \%)$ & $14 / 44(31.8 \%)$ & $34 / 94(36.2 \%)$ & .70 \\
\hline Delayed WMC GET > $5 \mathrm{~h}$ & $81 / 201(40.3 \%)$ & $34 / 66(51.5 \%)$ & $42 / 128(32.8 \%)$ & .01 \\
\hline Rapid WMC GET <1:45 h & 10/201 (5.0\%) & $2 / 66(3.0 \%)$ & $8 / 128(6.2 \%)$ & .50 \\
\hline WMC SBTT (h) & $4.05(3.19,5.39)$ & $3.55(2.85,4.69)$ & $4.12(3.30,5.68)$ & .01 \\
\hline Delayed WMC CTT >59 h & $55 / 164(33.5 \%)$ & $17 / 49(34.7 \%)$ & $36 / 111(32.4 \%)$ & .86 \\
\hline WMC delays in $\geq 2$ regions & $38 / 163(23.3 \%)$ & $10 / 47(21.3 \%)$ & $26 / 113(23.0 \%)$ & 1.00 \\
\hline \multicolumn{5}{|l|}{ Contractility measures } \\
\hline Gastric contractions/h & $56(27,119)$ & $49(35,120)$ & $56(24,119)$ & .70 \\
\hline Reduced gastric contractions $(<29 / \mathrm{h})$ & $41 / 160(25.6 \%)$ & $9 / 45$ (20.0\%) & $31 / 107(29.0 \%)$ & .31 \\
\hline Gastric motility index (MI) & $11.5(10.3,12.6)$ & $11.6(10.4,12.6)$ & $11.5(9.9,12.6)$ & .67 \\
\hline Reduced gastric MI (<9.82) & $33 / 154(21.4 \%)$ & $6 / 45(13.3 \%)$ & $26 / 107(24.3 \%)$ & .19 \\
\hline Small bowel contractions/h & $137.5(67,230)$ & $148(86,303)$ & $136(65,206)$ & .17 \\
\hline
\end{tabular}

$\mathrm{N}$, sample size; IQR, interquartile range.

exact test for categorical measures. $T$ tests compared symptoms by high vs low categories of gastric, small bowel, and colon contractions. Patients with normal vs delayed WMC GET were compared graphically using medians (IQRs) to 4-hour solid and 1-hour liquid retention percentages, SBTT, and CTT. Symptom profiles were plotted as means and $95 \%$ confidence intervals by normal vs delayed GET, SBTT, and CTT. Nominal, two-sided $P$-values with no adjustments for multiple comparisons are presented; comparisons were hypothesis-driven. Analyses were performed using SAS (version 9.3; SAS Institute, Cary, NC, USA) and Stata (Release 13, Stata Corporation, College Station, TX, USA) software.

\section{3 | RESULTS}

\section{1 | Transit and contractility abnormalities}

Figure 1 shows recordings from patients with (A) normal transit, $(B)$ mildly delayed GET (5 hours, 32 minutes), (C) severely delayed GET (90 hours, 32 minutes), (D) delayed CTT (>136 hours, 21 minutes), and (E) diffusely delayed GET (10 hours, 32 minutes), SBTT (13 hours, 21 minutes), and CTT (94 hours, 16 minutes).

Transit determinations for the whole group included patients with diabetic, idiopathic, and postfundoplication etiologies. Delayed solid (4-hour retention) and liquid (1-hour retention) scintigraphic gastric emptying were observed in $68.8 \%$ and $34.8 \%$ of patients, respectively (Table 1). WMC transit abnormalities including delayed and rapid transit were found in $73.3 \%$. Delays were noted in $66.3 \%$ including delayed GET in $40.3 \%$, SBTT in $15.5 \%$, and CTT in $33.5 \%$. Generalized delays involving $\geq 2$ of the 3 regions were observed in $23.3 \%$. Severe GET delays were found in $28.8 \%$ of patients. Fifty-eight of 132 patients with delayed scintigraphy had delayed WMC GET (43.9\% positive agreement) while 42 of 60 with normal scintigraphy had normal GET $(70.0 \%$ negative agreement). Overall agreement between 4-hour scintigraphic retention and GET was $52.8 \%$ with a kappa of $0.12(95 \% \mathrm{Cl} 0.002,0.23)$; agreement between 2 -hour scintigraphic retention and GET was $58.7 \%$ with a kappa of $0.16(95 \% \mathrm{Cl} 0.02,0.29)$. Rapid gastric scintigraphy was found in 6 of 188 (3.2\%). Rapid GET was noted in 
(A) Solid gastric emptying

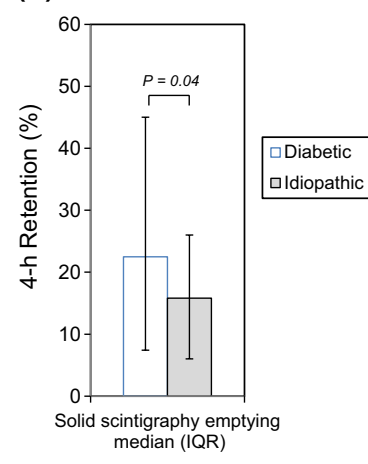

(B) Liquid gastric emptying

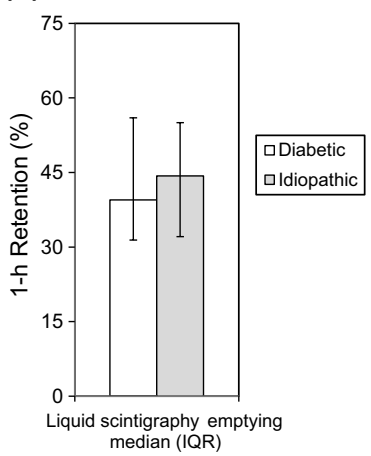

(C) WMC gastric emptying

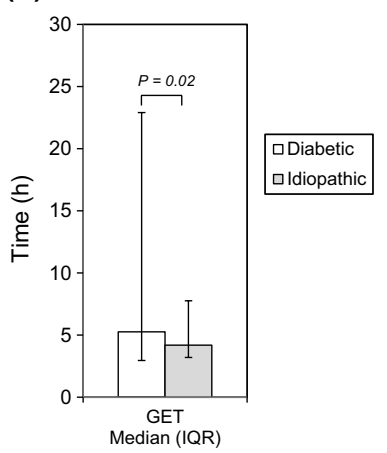

FIGURE 2 Disease etiologies were related to solid (A) and liquid (B) scintigraphic gastric emptying and WMC GET (C). Solid scintigraphic gastric retention $(P=.02)$ and WMC GET $(P=.04)$ values were greater among diabetic (open bars) versus idiopathic (gray bars) patients, while liquid scintigraphic emptying was not different between etiologies
10 of $200(5.0 \%)$, SBTT in 8 of 168 (4.8\%), and colon in 6 of 169 (3.6\%) patients.

Numbers of WMC contractions and $\mathrm{MI}$ in each region are shown in Table 1. Reduced numbers of gastric contractions and gastric MI were found in $25.6 \%$ and $21.4 \%$, and decreased numbers of small bowel contractions and small bowel MI were noted in $13.7 \%$ and $16.4 \%$, respectively.

Data acquisition was incomplete in small numbers of patients. No reliable WMC transit data were acquired in 5 of 201 (2.5\%). The WMC remained in the stomach during the entire recording in 9 of 196 (4.6\%), reflecting profound GET delays. Anal expulsion did not occur during the recording in 34 of 196 (17.3\%) preventing definitive CTT determination. However, it was possible to determine that CTT was delayed in 24 of 34 (70.6\%) of those cases in which anal expulsion was not observed. Transient data loss was noted in 27 of 196 (13.8\%) preventing accurate transit determination in at least one region.

\subsection{Relation of scintigraphy and WMC measures to etiology}

Subgroup analyses relating to etiology focused on comparisons between diabetic versus idiopathic patients and excluded the small number of postfundoplication patients. Solid scintigraphic gastric retention was greater in diabetic versus idiopathic patients $(P=.04)$; liquid emptying was not different between etiologies (Figure 2A,B). Diabetics had longer WMC GETs (Figure $2 C)(P=.02)$, and more diabetics exhibited delayed GETs $(P=.01)$ vs idiopathic patients $(P=.01)$ (Table 1). Overall agreement between 4-hour scintigraphic retention and GET in diabetics was $57.6 \%$ with a kappa of $0.14(95 \% \mathrm{Cl} 0.0$, 0.36 ), while agreement in idiopathic patients was $49.2 \%$ with a kappa of 0.09 (95\% $\mathrm{Cl} 0.0,0.22$ ). Agreements were not significantly different between etiologies $(P=.64)$. Conversely, SBTTs were longer in idiopathic patients $(P=.01)$. No other WMC transit or contractility measure related to etiology (Table 1 ).

\section{3 | Relation of gastric emptying to other measures}

Scintigraphic solid gastric retention was greater in patients with delayed $(N=118)$ vs normal $(N=76)$ GET $(P=.001)$ (Figure 3A). Liquid scintigraphic retention also was higher with delayed GET $(P=.02)$ (Figure 3B). Percentages of patients with solid scintigraphic delays trended higher with delayed versus normal GET $(P=.08)$; percentages with severely delayed solid emptying were greater with delayed GET $(P=.007)$ (Table 2). Percentages of patients with delayed liquid scintigraphy were similar with delayed and normal GET.

SBTT and CTT values were similar in patients with delayed $(\mathrm{N}=53)$ vs normal $(\mathrm{N}=110)$ GET (Figures 3C,D). SBTT delays $(P=.04)$ but not CTT delays were more prevalent among those with GET delays (Table 2).

Numbers of gastric contractions in the hour before capsule emptying were lower with delayed GET $(P=.02)$ and percentages of patients with low contraction numbers were higher with delayed versus normal GET ( $P=.0003$ ) (Table 2). Gastric Mls in the hour before capsule emptying were lower with delayed GET $(P=.0004)$, and percentages with low MI were greater with delayed versus normal GET $(P=.01)$. Numbers of colon contractions/hour were lower with delayed GET $(P=.02)$. Numbers of small bowel contractions and $\mathrm{MI}$ and percentages with reductions in small bowel contractions and MI were not different with delayed versus normal GET.

GET, SBT, and CTT values and percentages of patients with regional WMC delays were similar with delayed versus normal scintigraphic emptying (Table 3). Numbers of gastric, small bowel, and colon contractions and $\mathrm{MI}$ and percentages with reductions in contractions and $\mathrm{MI}$ in the three regions were not different with delayed versus normal scintigraphy (Table 3).

\subsection{Relation of regional transit and contractility to symptoms}

Overall GCSI and PAGI-SYM subscale scores for nausea/vomiting, early satiety/postprandial fullness, bloating/visible distention, and upper and lower abdominal pain/discomfort were not different with delayed versus normal GET, SBTT, and CTT (Figure 4A-C). Constipation scores were higher in patients with delayed CTT $(P=.03)$; diarrhea scores were lower in patients with delayed SBTT $(P=.04)$ and with delayed CTT $(P=.01)$ (Figure 4D-F).

PAGI-SYM upper abdominal pain/discomfort subscale scores were greater in patients with higher versus lower numbers of colon contractions ( $P=$.03) (Table 4). Overall GCSI scores and nausea/vomiting, early satiety/postprandial fullness, and bloating/distention subscale scores were not different in relation to any contractility measure. Lower abdominal pain/discomfort subscale $(P=.02)$ and constipation scores $(P=.03)$ were greater in those with higher vs lower colon contraction numbers. 


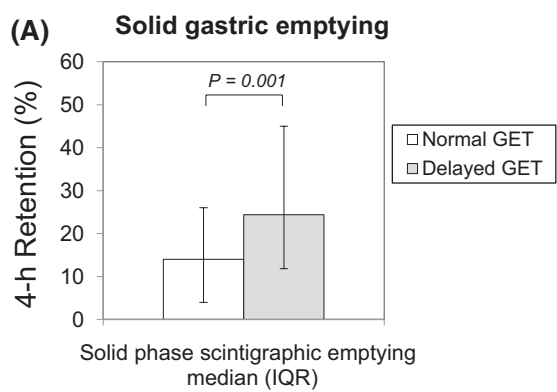

(C) Small bowel transit time

FIGURE 3 Solid (A) and liquid (B) gastric emptying were compared with normal (open bars) versus delayed (gray bars) WMC GETs. Solid $(P=.001)$ and liquid $(P=.02)$ retentions were greater with delayed GETs. SBTT (C) and CTT (D) were compared with normal (open bars) versus delayed (gray bars) GETs. Extragastric transit was not different in relation to GET

TABLE 2 Relation of WMC GET to abnormalities of other measures
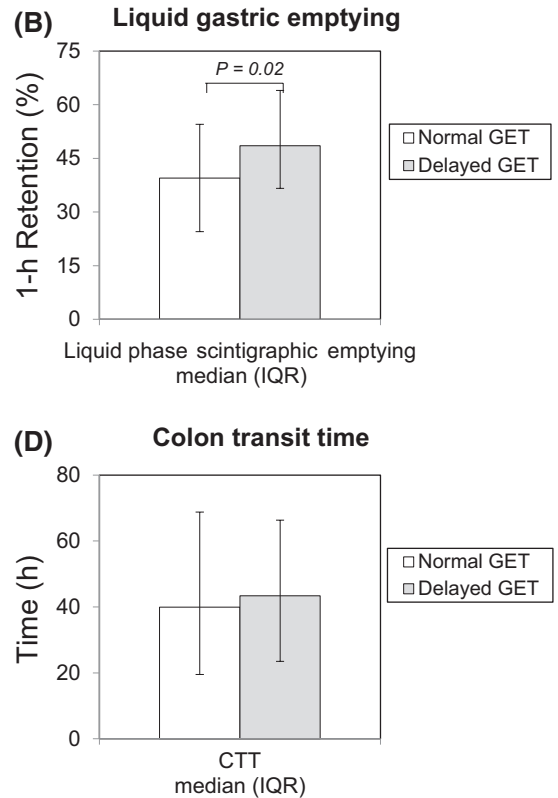

\begin{tabular}{|c|c|c|c|}
\hline Measure & $\begin{array}{l}\text { Normal GET ( } \leq 5 \mathrm{~h}) \\
\mathrm{N}(\%)\end{array}$ & $\begin{array}{l}\text { Delayed GET (>5 h) } \\
\mathrm{N}(\%)\end{array}$ & $P$ value \\
\hline \multicolumn{4}{|l|}{ Transit measures } \\
\hline $\begin{array}{l}\text { Delayed scintigraphic solid gastric } \\
\text { emptying (>10\% 4-h retention) }\end{array}$ & $74 / 116(63.8 \%)$ & $58 / 76(76.3 \%)$ & .08 \\
\hline $\begin{array}{l}\text { Severely delayed scintigraphic solid } \\
\text { gastric emptying (>35\% 4-h retention) }\end{array}$ & $18 / 116(15.5 \%)$ & $25 / 76(32.9 \%)$ & .007 \\
\hline $\begin{array}{l}\text { Delayed scintigraphic liquid gastric } \\
\text { emptying (>50\% 1-h retention) }\end{array}$ & $26 / 84(31.0 \%)$ & $22 / 54(40.7 \%)$ & .27 \\
\hline Delayed WMC SBTT (>6 h) & $12 / 110(10.9 \%)$ & $13 / 53(24.5 \%)$ & .04 \\
\hline Delayed WMC CTT (>59 h) & $36 / 106(34.0 \%)$ & $17 / 54(31.5 \%)$ & .53 \\
\hline \multicolumn{4}{|l|}{ Contractility measures } \\
\hline Gastric contractions/h & $64(38,130)$ & $35(11,61)$ & .02 \\
\hline Reduced gastric contractions $(<29 / \mathrm{h})$ & 18/105 (17.1\%) & $23 / 50(46.0 \%)$ & .0003 \\
\hline Gastric motility index (MI) & $11.7(10.7,12.7)$ & $10.6(8.7,11.9)$ & .0004 \\
\hline Reduced gastric MI $(<9.82)$ & $16 / 105$ (15.2\%) & $17 / 50(34.0 \%)$ & .01 \\
\hline Small bowel contractions/h & $138(77,223)$ & $124(63,255)$ & .92 \\
\hline $\begin{array}{l}\text { Reduced small bowel contractions } \\
(<36 / \mathrm{h})\end{array}$ & $13 / 104(12.5 \%)$ & $7 / 45$ (15.6\%) & .81 \\
\hline Small bowel motility index (MI) & $12.7(11.6,13.8)$ & $12.6(11.3,14.0)$ & .74 \\
\hline Reduced small bowel MI (<10.57) & $16 / 104(15.4 \%)$ & $8 / 45$ (17.8\%) & .92 \\
\hline Colon contractions $/ \mathrm{h}$ & $130(91,192)$ & $115(86,139)$ & .02 \\
\hline
\end{tabular}

$\mathrm{N}$, sample size

\section{DISCUSSION}

This investigation is the largest, most comprehensive prospective analysis of gastric plus extragastric transit abnormalities in suspected gastroparesis using WMC methods. Although WMCs are employed much less often than scintigraphy to measure gastric emptying, our sample size compared favorably to many large published studies using gastric scintigraphy. ${ }^{27-29}$ Additional strengths of this study included its multicenter structure with recruitment of well characterized patients, its separate analyses of diabetic versus idiopathic etiologies, its standardized analyses of diverse transit and contractility measures, and its association of motor findings to symptom profiles using validated surveys.

As in the initial study comparing scintigraphic and WMC findings in patients with prior diagnoses of gastroparesis, solid-phase gastric emptying measured by scintigraphy correlated with WMC GETs in 


\begin{tabular}{|c|c|c|c|}
\hline Measure & $\begin{array}{l}\text { Normal 4-h scintigraphy } \\
\text { Median (IQR) or } \mathrm{N}(\%)\end{array}$ & $\begin{array}{l}\text { Delayed 4-h scintigraphy } \\
\text { Median (IQR) or N (\%) }\end{array}$ & $P$ value \\
\hline \multicolumn{4}{|l|}{ Transit measures } \\
\hline WMC GET (h) & $4.0(3.0,14.8)$ & $4.6(3.2,14.9)$ & .36 \\
\hline Delayed WMC GET (>5 h) & $18 / 60(30.0 \%)$ & $58 / 132(44.0 \%)$ & .09 \\
\hline WMC SBTT (h) & $4.12(3.23,5.43)$ & $3.97(3.15,5.37)$ & .49 \\
\hline $\begin{array}{l}\text { Delayed WMC SBTT } \\
(>6 \mathrm{~h})\end{array}$ & $9 / 49$ (18.4\%) & $16 / 114(14.0 \%)$ & .48 \\
\hline WMC CTT (h) & $38.7(19.6,74.0)$ & $41.9(21.9,65.0)$ & .65 \\
\hline $\begin{array}{l}\text { Delayed WMC CTT } \\
(>59 \mathrm{~h})\end{array}$ & $18 / 50$ (36.0\%) & $35 / 110(31.8 \%)$ & .53 \\
\hline \multicolumn{4}{|l|}{ Contractility measures } \\
\hline Gastric contractions/h & $56.0(29.0,104.0)$ & $54.0(24.0,120.0)$ & .80 \\
\hline $\begin{array}{l}\text { Reduced gastric } \\
\text { contractions }(<29 / \mathrm{h})\end{array}$ & $9 / 43(20.9 \%)$ & $31 / 109$ (28.4\%) & .42 \\
\hline Gastric motility index (MI) & $11.5(10.7,12.5)$ & $11.4(9.9,12.6)$ & .40 \\
\hline $\begin{array}{l}\text { Reduced gastric } \mathrm{MI} \\
(<9.82)\end{array}$ & $5 / 43(11.6 \%)$ & 27/109 (24.8\%) & .08 \\
\hline $\begin{array}{l}\text { Small bowel } \\
\text { contractions } / \mathrm{h}\end{array}$ & $155.0(112.0,231.0)$ & $129.0(61.0,222.0)$ & .24 \\
\hline $\begin{array}{l}\text { Reduced small bowel } \\
\text { contractions }(<36 / \mathrm{h})\end{array}$ & $2 / 39$ (5.1\%) & $18 / 107(16.8 \%)$ & .10 \\
\hline $\begin{array}{l}\text { Small bowel motility } \\
\text { index (MI) }\end{array}$ & $12.9(12.3,14.0)$ & $12.6(11.1,13.9)$ & .16 \\
\hline $\begin{array}{l}\text { Reduced small bowel MI } \\
(<10.57)\end{array}$ & $3 / 39$ (7.7\%) & $21 / 107$ (19.6\%) & .13 \\
\hline Colon contractions/h & $138(90,162)$ & $126(84,162)$ & .55 \\
\hline
\end{tabular}

TABLE 3 Relation of regional transit and contractility to delayed versus normal scintigraphic gastric emptying

$\mathrm{N}$, sample size; IQR, interquartile range.

our investigation. ${ }^{5}$ We expanded on this by showing additional associations of liquid emptying with GETs. Unexpected findings of the present investigation included a device agreement of only $52.8 \%$ between WMC and scintigraphic gastric emptying measures and a lower prevalence of emptying delays with WMC versus nuclear medicine tests. In the original report, correlations were stronger $(R=0.73)$ and WMCs detected $21 \%$ more delays than scintigraphy. ${ }^{5}$ There are several potential explanations for these differences between the two studies. Most importantly, WMC and scintigraphic tests were performed on separate days in the current investigation while they were concurrent in the initial investigation. Coefficients of variability of up to $31 \%$ are seen on serial gastric emptying measurements regardless of the method of testing, suggesting that emptying rates are inconsistent from day to day in health and in gastroparesis. ${ }^{4,5,30}$ Thus, much of the disparity between our investigation and the Kuo study may relate to different day testing. Secondly, it is established that gastric emptying of digestible solids like the egg substitute meals ingested during scintigraphy is mediated by different mechanisms (ie, fed motor pattern) than for indigestible solids like the WMC (fasting migrating motor complexes). ${ }^{31,32}$ This raises the possibility that emptying rates measured by the two techniques may be inherently different. Thirdly, although the caloric composition of the nutrient bars ingested during WMC testing in this study is similar to the egg substitute meals consumed with scintigraphy, subtle differences in emptying profiles have been reported for the two meals. ${ }^{23}$ However, the magnitude of the difference in gastric emptying rates between the two meals is likely too small to explain the disparate observations of the current study and the original report. This discrepancy will be addressed by ongoing multicenter studies comparing the two techniques when performed simultaneously in patients believed to have gastroparesis. These large, prospective investigations will definitively determine whether stratification of patients into those with and without delayed gastric emptying is substantially different with the two methods.

We also confirmed extragastric WMC transit delays previously documented in studies employing less rigorous patient characterizations. ${ }^{13,14}$ Small bowel and colon delays were found in $>40 \%$ of patients with suspected gastroparesis, and more than $20 \%$ exhibited generalized impairments. SBTT delays were associated with GET delays suggesting possible common motor impairments across gut regions but did not correlate with gastric scintigraphy delays. This finding is consistent with the different physiology of indigestible versus digestible solid emptying. ${ }^{31,32}$ A novel finding of our study was its characterization of rapid transit in different regions in small numbers of patients with suspected gastroparesis. ${ }^{23}$ Others have observed rapid gastric emptying in up to $41 \%$ patients with dyspepsia using 
UPPER GI SYMPTOMS

(A) WMC gastric emptying

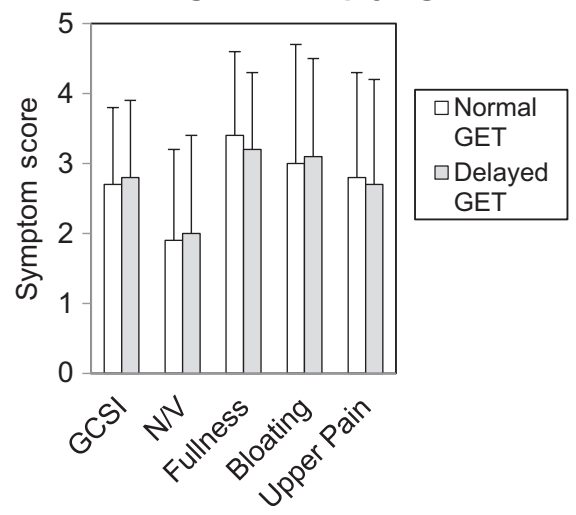

(D) WMC gastric emptying
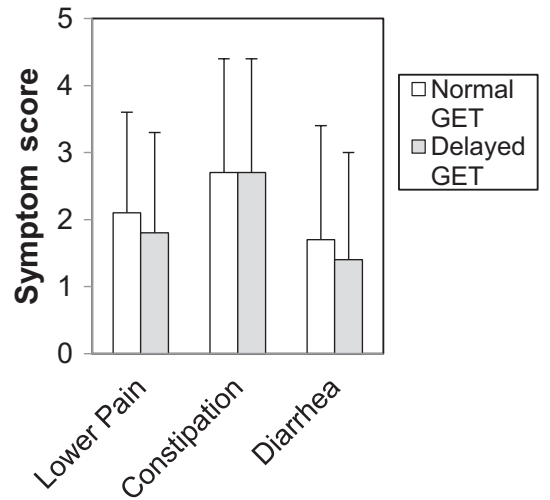

(B) WMC SB transit
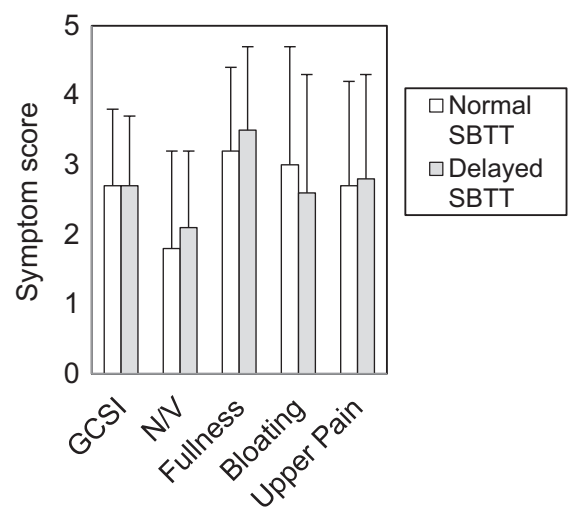

LOWER GI SYMPTOMS

(E) WMC SB transit

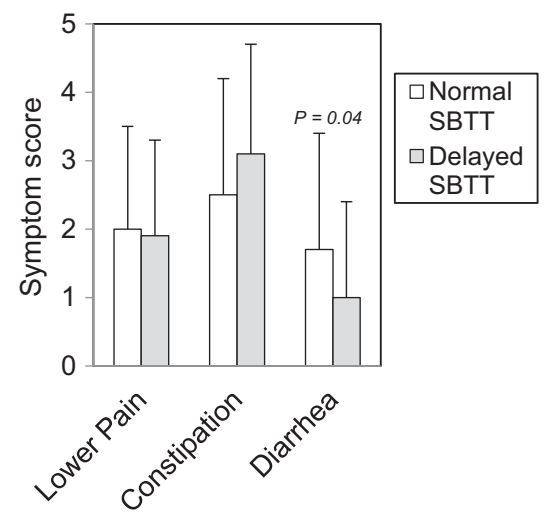

(C) WMC colon transit

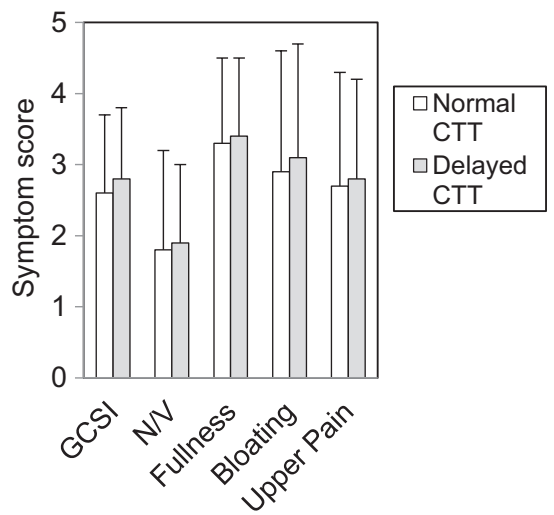

(F) WMC colon transit

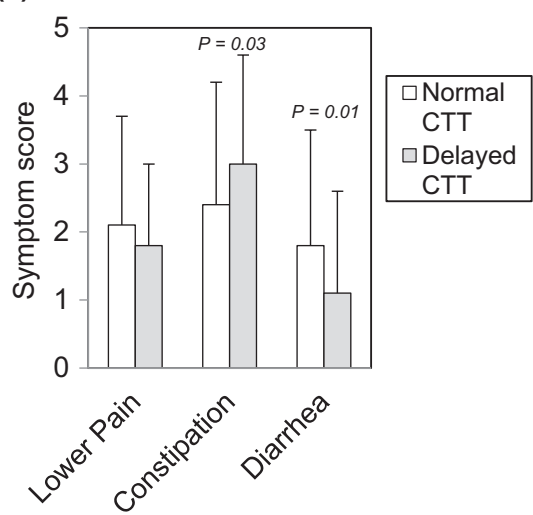

FIGURE 4 Overall GCSI and subscale scores for nausea/vomiting (N/V), early satiety/fullness (Fullness), bloating/distention (Bloating), and upper abdominal pain/discomfort (Upper Pain) were not different with delayed versus normal GET, SBTT, or CTT (A-C). Lower abdominal pain/discomfort subscale scores (Lower Pain) were similar with delayed and normal GET, SBTT, and CTT. Constipation scores were higher with delayed CTT $(P=.03)$; diarrhea scores were lower with delayed SBTT $(P=.04)$ and CTT $(P=.01)(\mathrm{D}-\mathrm{F})$

TAB LE 4 Relation of symptoms to contractility measures

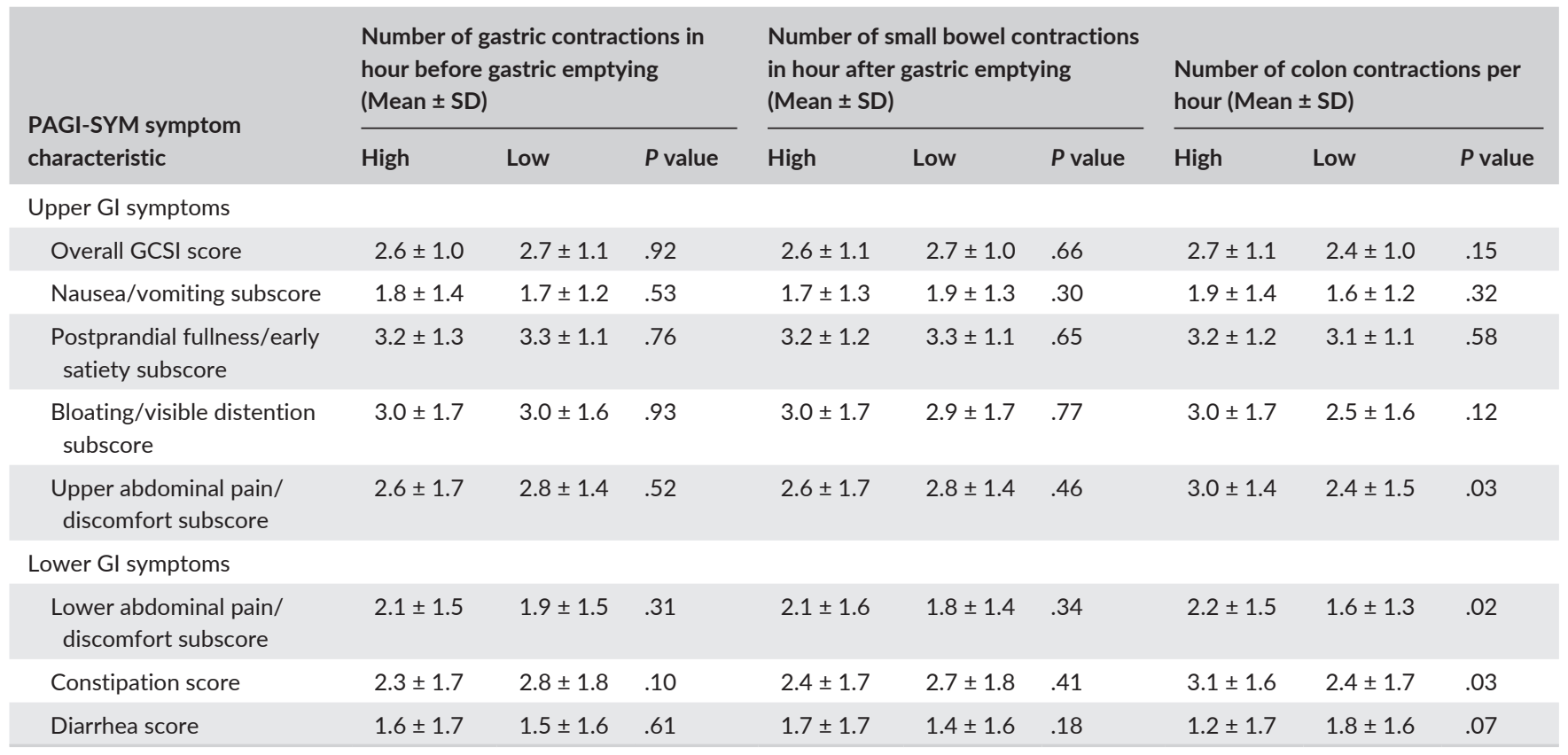


scintigraphy, but none have examined rapid WMC transit. ${ }^{33,34}$ In this investigation, rapid transit was found in too few patients (5\%) for subgroup analyses.

Novel regional contractility findings were acquired from our WMC pressure data. The association of delayed GET with reduced gastric but not small bowel contractions contrasts with an earlier study in which small bowel and gastric contractility were decreased only with GET $>12$ hours. ${ }^{16}$ However, that investigation only included 8 patients with mildly delayed GET ( $<12$ hours) and was too small to be definitive. Decreases in colon contractions related to delayed GET but not scintigraphic gastric emptying. Similarly, reduced numbers of colon contractions were noted in diabetics with delayed GET in post hoc analyses of the original WMC investigation, supportive of diffuse dysfunction in some patients with gastroparesis symptoms. ${ }^{5,17}$ The present study extended these findings to idiopathic patients. The preservation of normal small bowel contractions and $\mathrm{MI}$ in those with delayed GET suggests this gut region is less susceptible to disruption in patients with generalized dysmotility.

Our large sample allowed us to contrast transit and contractility in idiopathic disease versus diabetes. Prior studies showed no gastric scintigraphy differences between etiologies, but we found more severe emptying delays in diabetics versus idiopathic patients using both WMCs and scintigraphy. ${ }^{9}$ However, device agreements between scintigraphy and WMCs were similar in diabetic and idiopathic patients. Furthermore, SBTTs were shorter in diabetics than in idiopathic patients. Physiologic studies have noted differences in gastric $\mathrm{pH}$ and pancreatic polypeptide release in diabetic versus idiopathic gastroparesis suggesting more severe vagal impairments with diabetes. ${ }^{35,36}$ Our findings support differential pathogenesis of transit impairments in relation to etiology, perhaps secondary to different degrees of vagal dysfunction.

The comprehensive associations of symptoms with transit and contractility included in this study complement detailed published observations by the Gastroparesis Consortium relating symptoms to scintigraphic gastric emptying. ${ }^{18}$ Gastroparesis symptoms showed little correlation with GETs or other WMC transit or contractility measures; only numbers of colon contractions positively associated with upper abdominal pain severity. These findings suggest symptoms of gastroparesis are not solely determined by gastric, small intestinal, or colon transit. Furthermore, these observations are at odds with a prior smaller study reporting higher global gastroparesis symptoms with reduced small bowel contractions. ${ }^{19}$ Individual symptoms were not examined in that previous investigation. Similarly, another study employing dichotomous symptom assessments found no symptom correlation with WMC measures. ${ }^{12}$

This investigation raises new questions about CUNV pathogenesis. We hypothesized that WMC testing would uncover distinct extragastric transit or contractile profiles in patients with normal gastric scintigraphy given the symptom overlaps of gastroparesis and the lower functional bowel disorders. ${ }^{8,9}$ However, no WMC small bowel or colon transit or contractility abnormalities were specific for those with normal scintigraphy suggesting that no regional transit or phasic motor pattern is definitive for symptom genesis in CUNV. These findings warrant consideration of other pathophysiologic contributors including impaired gastric accommodation, altered luminal sensation, myoelectric dysfunction, or central nervous system abnormalities not detectable by gastric emptying testing as causes of CUNV pathogenesis. ${ }^{37-39}$

Our analyses associated lower $\mathrm{Gl}$ symptoms in patients with suspected gastroparesis to WMC transit and contractility. In contrast to gastroparesis symptoms, diarrhea related to rapid SBTT and CTT while constipation scores were higher in those with delayed CTT and increased colon contractions and lower abdominal pain correlated with higher colon contractility. These findings parallel a prior WMC study, in which patients with constipation-predominant irritable bowel syndrome showed greater contractility than those with functional constipation. $^{24}$

This investigation had limitations. Although most agents affecting transit were discontinued for study conduct, some maintenance medications (eg antihypertensives, antidepressants) might have influenced WMC measures. Because patients returned data recorders 4-7 days after WMC ingestion, definitive CTT determination was not possible in some individuals. However, in more than two-thirds of these patients, we were still able to diagnose delayed CTT. It would have been impractical to lengthen the data collection period to define CTT in the remainder. Glycemic control was not monitored in diabetics; thus, acute hyperglycemic effects on transit or contractility cannot be excluded. ${ }^{40}$ Despite drawbacks, these important findings provide a foundation for additional investigations defining impacts of WMC performance on patient management. As with other methods of emptying testing including scintigraphy, there are few published studies which objectively demonstrate that quantifying the rate of gastric emptying influences any symptom or resource utilization outcome in suspected gastroparesis. However in one investigation, scintigraphic gastric retention $>20 \%$ was associated with superior outcomes versus milder impairments supporting the utility of emptying testing. ${ }^{41}$ Future studies will define whether WMC testing leads to different treatment decisions versus scintigraphy. Further, it is uncertain whether treating small bowel or colon transit or contractility abnormalities detected by WMC testing has additional impact on patient outcomes. In an uncontrolled pediatric study, osmotic laxatives reduced gastric emptying delays and improved dyspeptic symptoms in children with functional dyspepsia. ${ }^{42}$ Larger controlled trials could validate the concept that gastroparesis improves with treatments targeting distal gut dysfunction.

In conclusion, WMCs define similar but not identical gastric emptying delays as scintigraphy which are more severe in diabetics and correlate with reduced gastric and colon contractility. Extragastric or generalized transit delays occur in $>40 \%$ of patients with gastroparesis symptoms. Upper Gl symptoms correlate poorly with WMC defects and do not distinguish gastroparesis from CUNV, although lower GI symptoms associate with transit and contractility abnormalities. These findings provide insight into gastroparesis pathogenesis and form a basis for future investigations studying the impact of WMC testing on clinical care. 


\section{ACKNOWLEDGMENTS}

Members of the Gastroparesis Clinical Research Consortium: The members of the Gastroparesis Clinical Research Consortium include the authors as well as study coordinators and co-investigators who contributed to the research by assisting in subject recruitment, data input, and maintenance of the Gastroparesis Registry databases.

Clinical Centers: Johns Hopkins University, Baltimore, MD; Pankaj Jay Pasricha, MD (Principal Investigator); John Clarke, MD; Yale Kim, MHS MS. Stanford University, Stanford, CA: Linda Nguyen, MD (Principal Investigator); Nighat Ullah, MD. California Pacific Medical Center, San Francisco, CA: William Snape, MD (Principal Investigator); Nata DeVole, RN; Mary Greene (2009-2011); Candice Lee; Courtney Ponsetto (2009-2010); Katerina Shetler, MD. Temple University, Philadelphia, PA: Henry P. Parkman, MD (Principal Investigator); Steven Kantor; Vanessa Lytes, MSN CRNP; Amiya Palit, MD; Kellie Simmons, NP. Texas Tech University Health Sciences Center, El Paso, TX: Richard W. McCallum, MD (Principal Investigator); Reza Hejazi, MD (2009-2011); Kathy Roeser (2008-2009); Irene Sarosiek, MD; Denise Vasquez, RN; Natalia Vega, RN. University of Louisville, Louisville, KY: Thomas Abell, MD (Principal Investigator); Karen Beatty, RN; Lisa Hatter, RN; Ronna Howard; Lindsay Nowotny, PA-C. University of Mississippi Medical Center, Jackson, MS: Shou Tang, MD (Principal Investigator); Om S Amin, MD (2010-2011); Olivia Henry, MS RD; Archana Kedar, MD; Valerie McNair (2008-2012); Susanne Pruett, RN (2007-2008); Margaret Smith, RN; Danielle Spree, RN (2007-2010). University of Michigan, Ann Arbor, MI: William Hasler, MD (Principal Investigator); Michelle Castle (2008-2011); Radoslav Coleski, MD (2007-2009); Sophanara Wootten. Wake Forest University, Winston-Salem, NC: Kenneth Koch, MD (Principal Investigator); Lynn Baxter; Anya Brown; Samantha Culler (2009-2012); Judy Hooker; Paula Stuart, PA. Resource Centers: Mayo Clinic College of Medicine (Pathology Analyses Center), Rochester, MN: Gianrico Farrugia, MD (Principal Investigator); Madhusudan Grover, MD, Cheryl Bernard, Matthew Lurken. MetroHealth Medical Center, Cleveland, $\mathrm{OH}$ : Jorge Calles-Escandon, MD. National Institute of Diabetes, Digestive and Kidney Diseases, Bethesda, MD: Jose Serrano, MD, PhD (Program Official); Frank Hamilton, MD, MPH (Project Scientist); Steven James, MD; Rebecca Torrance, RN MSN; Rebekah Van Raaphorst, MPH. Johns Hopkins University, Bloomberg School of Public Health (Data Coordinating Center), Baltimore, MD: James Tonascia, $\mathrm{PhD}$ (Principal Investigator); Patricia Belt; Erin Corless Hallinan, MHS; Ryan Colvin, MPH (2007-2010); Michele Donithan, MHS; Mika Green, MA (2009-2012); Milana Isaacson; Wana Kim (2009-2011); Linda Lee, MD; Patrick May, MS; Laura Miriel; Alice Sternberg, ScM; Mark Van Natta, MHS; Ivana Vaughn, MPH; Laura Wilson, ScM; Katherine Yates, ScM.

\section{AUTHOR CONTRIBUTION}

WLH and KLK contributed to study design, subject recruitment, data collection, data analysis, manuscript preparation, and approval of final manuscript version; KPM and MVN contributed to study design, statistical analysis, manuscript preparation, and approval of final manuscript version; LAW contributed to statistical analysis, manuscript preparation, and approval of final manuscript version; HPP, PJP, KLK, TLA, RWM, LAN, WJS, IS and JOC performed study design, subject recruitment, data collection, contribution to manuscript preparation, and approval of final manuscript version; GF and JC-E performed study design, contribution to manuscript preparation, and approval of final manuscript version; MG and LM contributed to manuscript preparation and approval of final manuscript version; JT performed study design, statistical analysis, contribution to manuscript preparation, and approval of final manuscript version; LAL performed study design, statistical analysis, contribution to manuscript preparation, and approval of final manuscript version; FAH performed study design, grant administration, contribution to manuscript preparation, and approval of final manuscript version.

\section{DISCLOSURE}

None of the authors report any financial, professional, or personal conflict of interests that are relevant to this manuscript.

\section{ORCID}

W. L. Hasler (iD http://orcid.org/0000-0002-6158-2871

H. P. Parkman iD http://orcid.org/0000-0003-4904-4891

T. L. Abell iD http://orcid.org/0000-0002-3175-5161

\section{REFERENCES}

1. Hasler WL. Gastroparesis: pathogenesis, diagnosis and management. Nat Rev Gastroenterol Hepatol. 2011;8:438-453.

2. Abell TL, Camilleri M, Donohoe $\mathrm{K}$, et al. Consensus recommendations for gastric emptying scintigraphy: a joint report of the American Neurogastroenterology and Motility Society and the Society of Nuclear Medicine. Am J Gastroenterol. 2008;103:753-763.

3. Tougas G, Eaker EY, Abell TL, et al. Assessment of gastric emptying using a low fat meal: establishment of international control values. Am J Gastroenterol. 2000;95:1456-1462.

4. Szarka LA, Camilleri M, Vella A, et al. A stable isotope breath test with a standard meal for abnormal gastric emptying of solids in the clinic and in research. Clin Gastroenterol Hepatol. 2008;6:635-643.

5. Kuo B, McCallum RW, Koch KL, et al. Comparison of gastric emptying of a nondigestible capsule to a radiolabelled meal in healthy and gastroparetic subjects. Aliment Pharmacol Ther. 2008;27:186-196.

6. Stanghellini V, Chan FK, Hasler WL, et al. Gastroduodenal disorders. Gastroenterology. 2016;150:1380-1392.

7. Mearin F, Lacy BE, Chang L, et al. Bowel disorders. Gastroenterology. 2016;150:1393-1407.

8. Parkman HP, Yates K, Hasler WL, et al. Clinical features of idiopathic gastroparesis vary with sex, body mass, symptom onset, delay in gastric emptying, and gastroparesis severity. Gastroenterology. 2011;140:101-115.

9. Parkman HP, Yates K, Hasler WL, et al. Similarities and differences between diabetic and idiopathic gastroparesis. Clin Gastroenterol Hepatol. 2011;9:1056-1064.

10. Rao SS, Kuo B, McCallum RW, et al. Investigation of colonic and whole-gut transit with wireless manometry capsule and radioopaque markers in constipation. Clin Gastroenterol Hepatol. 2009;7:537-544. 
11. Camilleri $\mathrm{M}$, Thorne NK, Ringel $\mathrm{Y}$, et al. Wireless $\mathrm{pH}$-motility capsule for colonic transit: prospective comparison with radiopaque markers in chronic constipation. Neurogastroenterol Motil. 2010;22:874-882.

12. Arora Z, Parungao JM, Lopez R, Heinlein C, Santisi J, Birgisson S. Clinical utility of wireless motility capsule in patients with suspected multiregional gastrointestinal dysmotility. Dig Dis Sci. 2015;60:1350-1357.

13. Kuo B, Maneerattanaporn M, Lee AA, et al. Generalized transit delay on wireless motility capsule testing in patients with clinical suspicion of gastroparesis, small intestinal dysmotility, or slow transit constipation. Dig Dis Sci. 2011;56:2928-2938.

14. Rao SS, Mysore K, Attaluri A, Valestin J. Diagnostic utility of wireless motility capsule in gastrointestinal dysmotility. J Clin Gastroenterol. 2011;45:684-690.

15. Hasler WL. The use of SmartPill for gastric monitoring. Expert Rev Gastroenterol Hepatol. 2014;8:587-600.

16. Kloetzer L, Chey WD, McCallum RW, et al. Motility of the antroduodenum in healthy and gastroparetics characterized by wireless motility capsule. Neurogastroenterol Motil. 2010;22:527-533.

17. Coleski R, Wilding GE, Semler JR, Hasler WL. Blunting of colon contractions in diabetics with gastroparesis quantified by wireless motility capsule methods. PLoS ONE. 2015;10:e0141183.

18. Pasricha PJ, Colvin R, Yates K, et al. Characteristics of patients with chronic unexplained nausea and vomiting and normal gastric emptying. Clin Gastroenterol Hepatol. 2011;9:567-576.

19. Barshop K, Staller K, Semler J, Kuo B. Duodenal rather than antral motility contractile parameters correlate with symptom severity in gastroparesis patients. Neurogastroenterol Motil. 2015;27:339-346.

20. Hasler WL, May KP, Van Natta ML, et al. Wireless motility capsule gastric and extragastric transit and pressure characteristics in a large patient cohort with gastroparesis symptoms: relation to scintigraphic findings and disease etiology (abstract). Gastroenterology. 2015;148:S507-S508.

21. Hasler WL, May KP, Pasricha PJ, et al. Relation of gastroparesis symptom severity to gastric, small bowel, and colon transit and contraction profiles on wireless motility capsule testing in a large multicenter cohort (abstract). Gastroenterology. 2016;150:S725.

22. Sachdeva P, Malhotra N, Pathikonda M, et al. Gastric emptying of solids and liquids for evaluation for gastroparesis. Dig Dis Sci. 2011;56:1138-1146.

23. Wang YT, Mohammed SD, Farmer AD, et al. Regional gastrointestinal transit and $\mathrm{pH}$ studied in 215 healthy volunteers using the wireless motility capsule: influence of age, gender, study country and testing protocol. Aliment Pharmacol Ther. 2015;42:761-772.

24. Hasler WL, Saad RJ, Rao SS, et al. Heightened colon motor activity measured by a wireless capsule in patients with constipation: relation to colon transit and IBS. Am J Physiol Gastrointest Liver Physiol. 2009;297:G1107-G1114.

25. Rentz AM, Kahrilas P, Stanghellini V, et al. Development and psychometric evaluation of the patient assessment of upper gastrointestinal symptom severity index (PAGI-SYM) in patients with upper gastrointestinal disorders. Qual Life Res. 2004:13:1737-1749.

26. Revicki DA, Rentz AM, Dubois D, et al. Development and validation of a patient-assessed gastroparesis symptom severity measure: the Gastroparesis Cardinal Symptom Index. Aliment Pharmacol Ther. 2003;18:141-150

27. Stanghellini V, Tosetti C, Paternico A, et al. Risk indicators of delayed gastric emptying of solids in patients with functional dyspepsia. Gastroenterology. 1996;110:1036-1042.
28. Talley NJ, Locke GR, Lahr BD, et al. Functional dyspepsia, delayed gastric emptying, and impaired quality of life. Gut. 2006;55:933-939.

29. Cassilly DW, Wang YR, Friedenberg FK, Nelson DB, Maurer AH, Parkman HP. Symptoms of gastroparesis: use of the gastroparesis cardinal symptom index in symptomatic patients referred for gastric emptying scintigraphy. Digestion. 2008;78:144-151.

30. Cremonini F, Mullan BP, Camilleri M, Burton DD, Rank MR. Performance characteristics of scintigraphic transit measurements for studies of experimental therapies. Aliment Pharmacol Ther. 2002;16:1781-1790.

31. Camilleri M, Malagelada JR, Brown ML, Becker G, Zinsmeister AR. Relation between antral motility and gastric emptying of solids and liquids in humans. Am J Physiol. 1985;249:G580-G585.

32. Cassilly D, Kantor S, Knight LC, et al. Gastric emptying of a nondigestible solid: assessment with simultaneous SmartPill $\mathrm{pH}$ and pressure capsule, antroduodenal manometry, gastric emptying scintigraphy. Neurogastroenterol Motil. 2008;20:311-319.

33. Delgado-Aros S, Camilleri M, Cremonini F, Ferber I, Stephens D, Burton DD. Contributions of gastric volumes and gastric emptying to meal size and postmeal symptoms in functional dyspepsia. Gastroenterology. 2004;127:1685-1694.

34. Bharucha AE, Camilleri M, Forstrom LA, Zinsmeister AR. Relationship between clinical features and gastric emptying disturbances in diabetes mellitus. Clin Endocrinol. 2009;70:415-420.

35. Hasler WL, Coleski R, Chey WD, et al. Differences in intragastric $\mathrm{pH}$ in diabetic vs. idiopathic gastroparesis: relation to degree of gastric retention. Am J Physiol-Gastrointest Liver Physiol 2008;294:G1384-G1391.

36. Gaddipati KV, Simonian HP, Kresge KM, Boden GH, Parkman HP. Abnormal ghrelin and pancreatic polypeptide responses in gastroparesis. Dig Dis Sci. 2006;51:1339-1346.

37. Angeli TR, Cheng LK, Du P, et al. Loss of interstitial cells of Cajal and patterns of gastric dysrhythmia in patients with chronic unexplained nausea and vomiting. Gastroenterology. 2015;149:56-66.

38. Kumar A, Attaluri A, Hashmi S, Schulze KS, Rao SS. Visceral hypersensitivity and impaired accommodation in refractory diabetic gastroparesis. Neurogastroenterol Motil. 2008;20:635-642.

39. Karamanolis G, Caenepeel P, Arts J, Tack J. Determinants of symptom pattern in idiopathic severely delayed gastric emptying: gastric emptying rate or proximal stomach dysfunction? Gut. 2007;56:29-36.

40. MacGregor IL, Gueller R, Watts HD, Mayer JH. The effect of acute hyperglycemia on gastric emptying in man. Gastroenterology. 1976;70:190-196.

41. Pasricha PJ, Yates KP, Nguyen L, et al. Outcomes and factors associated with reduced symptoms in patients with gastroparesis. Gastroenterology. 2015;149:1762-1774.

42. Boccia G, Buonavolontà R, Coccorullo $P$, Manguso F, Fuiano L, Staiano A. Dyspeptic symptoms in children: the result of a constipation-induced cologastric brake? Clin Gastroenterol Hepatol. 2008;6:556-560.

How to cite this article: Hasler WL, Patrick May K, Wilson LA, et al. Relating gastric scintigraphy and symptoms to motility capsule transit and pressure findings in suspected gastroparesis. Neurogastroenterol Motil. 2018;30:e13196.

https://doi.org/10.1111/nmo.13196 